\title{
THE ROLE OF TACIT KNOWLEDGE IN THE FORMATION AND CONTINUATION OF ARCHITECTURAL PATTERNS CASE STUDY: GARDEN-HOUSES OF MEYBUD, IRAN
}

\author{
Ahmad DANAEINIA $^{1^{*}}$, Masoud HODAEI ${ }^{2}$ \\ ${ }^{1}$ Faculty of Architecture and Art, University of Kashan, Iran, Kashan \\ ${ }^{2}$ Architectural Engineering, University of Kashan, Iran, Kashan
}

Received 29 September 2018; accepted 15 March 2019

\begin{abstract}
Human has a dimension of knowledge named the tacit knowledge that the main important part of it is obtained through experience and direct connection with phenomena over time that turns into a pattern. Based on knowledge and intelligent use of it, the garden-house pattern appears to have an unbreakable bond with the nature and the understanding of both social and cultural rules of users. The research questions at first place discuss the role of tacit knowledge in shaping the architecture of garden-houses of Meybud and how this knowledge has appeared in architecture of garden-houses of Meybud. Qualitative research method and data collection method relies on library studies and field research. The results indicate that the patterns of housing in Meybud have shaped based on the recognition of two components of environment (the climate and natural context) and human (social norms), understanding of these two and applying them. The tacit knowledge and reliance on experiences is very influential and the garden-house pattern is institutionalized as the most sustainable pattern of architecture.
\end{abstract}

Keywords: Meybud, knowledge management, tacit knowledge, sustainable pattern, garden-house.

\section{Introduction}

In spite of the importance of tacit knowledge and its background (age), the study of it, dates back to the early twentieth century. This knowledge is a valuable skill and experience that has proven its efficiency and effectiveness over time (Oshtorian \& Emami Meybodi, 2010, p. 17) and it's been capable of turning into a "pattern" through time. Mankind has many patterns in his mind since the birth that guarantee the survival for him, and according to this essential principle of mind and the peripheral environment, consciously or unconsciously, mankind seeks order in disorder (Sharif \& Mohammad Ali Nejad, 2012, p. 56). In architecture, the pattern is a response to the needs for life that can accommodate life. After some time, it is the architecture that forms the function, because it has become pattern and has found an independent identity. These patterns are not objective elements like brick and door; they are much deeper and more fluid; they are pure and hidden essence, which every building and city is always made of them (Alexander, 2011). All of these patterns are made by humans and depend on the culture of societies. Each so- ciety and consequently every man has a background and is the result of its own history (Mohammadi Khabazan, 2016); therefore, inhabitants of Meybud has built gardenhouse on the basis of thousand years of experience and relying on a rich social and cultural system to fulfill residential and functional needs. This means that the inhabitants of Meybud, based on tacit knowledge, have achieved patterns in the construction of the house, which not only include its ecological dimension, but also the culture, social, and economic nature. According to Emami Meybodi (Meybud's traditional master), "Meybudi's architects have used the patterns for the design of garden-house in Meybud. Pattern is a source that people have believed in it and have improved and have developed it over time. These patterns are rooted in the experience of the past centuries and has continue to evolve as a cultural and technical basis as long as the society remains alive. Accordingly, the gardenhouse pattern in Meybud is based on experience and has been tested over time and adapted to local culture and the environment; therefore, it has dynamism and efficacy" (Interview with the professor in 2017).

*Corresponding author. E-mail: danaeinia@kashanu.ac.ir 


\section{Methodology}

The research's approach is qualitative and information gathered via library studies, field research and interview. In the interview section, the points of view of some of the architects of Meybud and the elder inhabitants have been investigated in relation to the factors of formation for garden-house pattern in Meybud. Then, by accidental choice, twelve of Meybud's habitant were picked up and asked to draw the subjective pattern of the desirable accommodation in order to study the efficiency of tacit knowledge on formation of Garden-house pattern.

\section{Research background}

The existing literature provides sufficient evidence to support the importance of tacit knowledge and many studies have been conducted in this regard. However, there is lacuna in the literature which will be uncovered through an extensive review in the following sections including how tacit knowledge is perceived in the literature and what its relevance is in multiple domains of knowledge management such as management strategy, organizational learning, storytelling, intellectual capital, communities of practice, knowledge networks, and information pulse communication technology. Following on, there is a significant gap with regards to the study of tacit knowledge in these fields and a number of related questions are presented for future research inquiry into the understanding the role of tacit knowledge phenomenon (Venkitachalam \& Busch, 2012, p. 357).

Webster's dictionary defines knowledge as the reality or the condition of knowing something through experience or cooperation (Mehr Alizadeh \& Abdi, 2011, p. 11). Aristotle has divided all sorts of knowledge into three categories of theoretical knowledge, construction knowledge, and functional knowledge according to their purposes (Arab, 2015, p. 4). Educating and understanding the resources of knowledge management has a considerable effect in the performance of individuals, and will contain multiple organizational and individual interests, such as creativity, flexibility, and problem solving. In addition, individuals are capable and self-control and self-regulation; hence, one factor effecting the ability of individuals is to use their capacities and knowledge of them. "Fayol" points out to this issue as expressing the management knowledge's position, this matter(management) must be learned (Iran Nezhad Parizi, quoted by Fayol, 2012, p. 50). According to wiig, tacit knowledge includes human behaviors, human attitudes and capabilities, business philosophy, patterns, operations, procedures, and sophisticated technologie (Wiig, 2002, p. 2). Accordingly, knowledge management strives to extract the accumulated data in the mind of the organizations members and share it among all the people. In this case, the stored knowledge in the system becomes a permanent usable resource and provides sustainability to the organization (Huysman, 2006, p. 41). Knowledge management, since it relies to the most valuable asset of any organization i.e intellectual capital, tries to discover hidden asset in the mind of individuals and transforms this hidden treasure into assets of an organization; so that a wide range of people are involved in decision-makings. The mechanism of this type of management is based on the creation of an organizational culture based on "creativity" and "innovation" (Heydari Tafreshi, Khadivi, \& Yousefi, 2012, p. 203), in which a set of process including: identifying, gaining, developing and applying appropriate knowledge; act at the proper time. In the formation of the cycle there is an immediate relationship between man, place and technology (Figures 1 and 2).

\section{Conceptual scope of tacit knowledge and its crystallization in architecture}

For the first time, "Polanyi", by stating "we know more than we say" introduced the concept of tacit knowledge. He has introduced tacit knowledge as an integral part of the knowledge and fundamental power of the mind (Oshtoran \& Emami Meybodi, 2010, p. 17). Nonaka and Takuchi explaining the traits of tacit knowledge have looked over the issue of language and learning, and they believe that teaching grammatical rules is required to learn a language at adult ages. While children and teenagers learn native language without learning the grammar rules (Nonaka \&

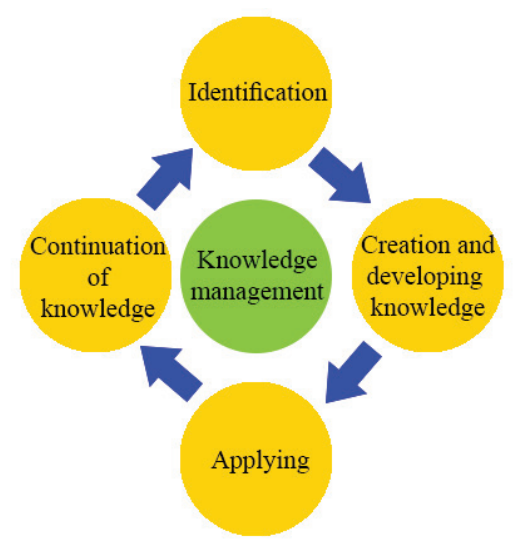

Figure 1. Relations of human, location and technology in knowledge management



Figure 2. Process of knowledge management (authors with approaches from Arab, 2015) 
Takeuchi, 1995). "Groff", "Hamel" and "Polanyi" state that according to the features of organizational knowledge, it can be divided into two parts: first, a very general type of knowledge known as "tacit knowledge" or "hidden knowledge", and the latter is a documented knowledge called "explicit knowledge". Tacit knowledge is the knowledge that is formed based on personal knowledge and based on individual experiences and include intangible factors such as personal beliefs, points of view and values (Farhoodi \& Dorurdi, 2008, p. 19) (Figure 3). Explicit knowledge is the tacit knowledge that is documented and is explicitly in the form of a formal language and is easily shared among individuals (Lazemi Chalak, Ansariyan, \& Mohammad Nejad, 2012, p. 2). Tacit knowledge is derived from external knowledge. Human being learn knowledge through personal and group experiences in outdoor, whether nature or human environments, and it is not noticeable and reliable until it is external, which means that we cannot speak of it and even the one who has experience has to state somehow so that it can be realizable. From then on, he combine the knowledge derived from the outside with the mental reserves from cultural, social and historical background and states opinions, writes or practices and shares his knowledge with others (Fadaei, 2016, p. 29). "Bossen" and "Dalsgaard" have considered tacit knowledge equivalent as a practical knowledge; "Willner", "Sternberg" and "Hedlund" also have considered tacit knowledge as practical knowledge associated with daily life. According to Smith, explicit knowledge implies a "trend" that deals with the organizing knowledge while tacit knowledge refers to "action" that adverts how the work is done (Smith, 2001, p. 311). "Miller", emphasizing on a need to engage people with the problem, considers empowerment as a process that everyone needs to create for themselves. In this way, people learn how to change their environment through action (Miller Mb, 1997, p. 662). Nonaka, Takuchi and Juri divide tacit knowledge in two dimensions: technical and mental (Mahroeian \& Forozia, 2012, p. 304) (Figure 4). The technical dimension of tacit knowledge includes pro-

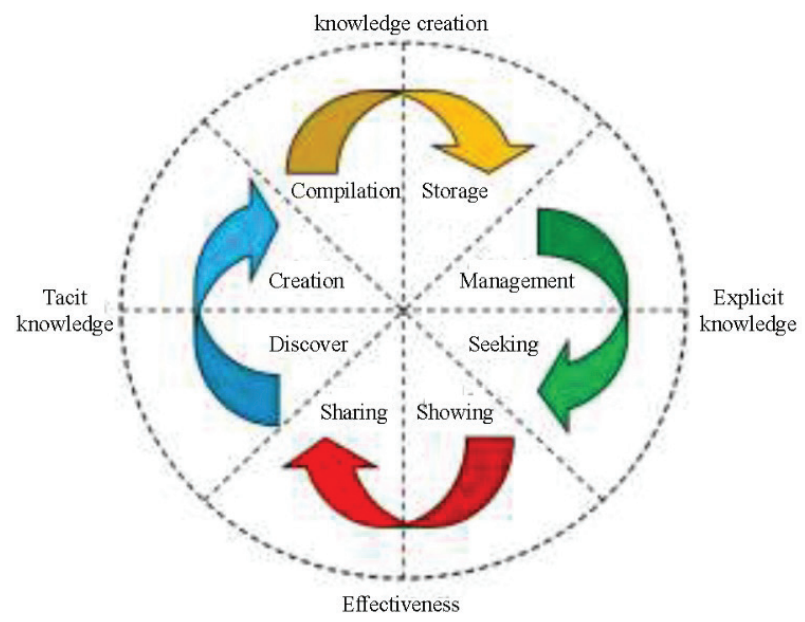

Figure 3. Dimensions of tacit knowledge (source: authors, 2018)



Figure 4. How to create knowledge (source: James, Albers, \& Trinidad, 2006)

fessions, unconventional and intangible skills and objective techniques; while the mental dimension, which is also called innate, includes subjective patterns, design, examples, angles, attitudes and innate imaginations in which the individual has no doubt about them. The subjective dimension of tacit knowledge reflects the individual's imagination of reality and its attitude towards the future. Nonaka and Takuchi emphasize that, although this knowledge is not easily expressed, it reflect the perception of individuals towards the world and is considered as an important element in the creation of modern knowledge (Oshtoran \& Emami Meybodi, 2010, p. 20).

In the tacit knowledge theory, knowledge of designing architecture can be divided into two type of personal and explicit knowledge. In this division, personal knowledge of designing is an unconscious and inexpressible knowledge that comes directly from experience. This kind of knowledge consists of two dimensions of skill and cognition. The skill dimension of designing knowledge is related to do designing skills. The cognitive dimension also relates to the recognition of the designing's position, which the subject of the project forms as a part of it. This typical knowledge is the knowledge that the designer gains gradually throughout his life time by experiencing the architecture examples. According to the definition, personal knowledge over the topic of design is the integrative perception that defines the preferences, beliefs and real feeling of the individual (Kalami, 2014).

\section{The role of tacit knowledge in shaping architectural patterns in Meybud}

The word "pattern" is now widely used in the Persian language, and the different fields of sciences have their own interpretations and definitions of pattern according to the present and need. Its general meaning is equal and synonymous with words such as "sample" and "model" (Soltani, Mansuri, \& Farzin, 2012, p. 78). The patterns are abstract, derived by common concepts and perceptions of men living in the environment that is defined by symbols, needs, and norms (Sameh, 2015, p. 30). In societies with a great historical background, patterns have been formed as roots in the deepest layers of the unconsciousness and consciousness, and also the patterns have shaped and lead many values, behaviors, expectations, preferences and desirability. These models and patterns have an undeniable share, even in the formation of the system and valuation 
to its totality. The ancient patterns or persistent fundamental notions, with their description, cannot be only in the physical form. They are, at the same time, both objective and subjective, and they are alive and dynamic (Barati \& Kakavand, 2016, p. 6). In fact, the architectural pattern is a kind of architecture that extracts the experiences of hundreds of years in the field of shape, position, direction, size, component relationships, materials, as a product of creativity and skill of experts, and yet this products are very identical a diverse at the same time. Diversity is the result of the difference in the shape and position of the earth, the economic situation and the social aspect of the employer and the taste of the architect and the similarity is the consequence of cultural, climatic, relations steadiness and social principles (Rahimi Ashtiani, 2012, p. 29). Accordingly, the simultaneous tacit of understanding problem and solution lead to their interconnection and the lack of severability and pattern generation in architecture (Nari Ghomi, Tehrani, Raja Ghomi, Abbaszadeh, \& Mahalatian, 2015, p. 33). Therefore, the significance of pattern as a method to describe tacit knowledge has recognized (Takashi, Sakamoto, \& Miyake, 2011, p. 47).

The type of housing (garden-house) is more associated with social stratification. Based on social strata and its role in shaping of housing pattern in Meybud, "Janeb Allahi" distinguishes four social strata of the "Bozorgoon", "AghiYun", "Rayat" and "Rayati" in Meybud and considered the traits of each of them. Housing has had the identic role for the Bozorgoon stratum due to the fact that it should clarify the social base of individual and boast its determination to others because housing in this stratum is a symbol of prosperity and supremacy, and each component should induce a massage: the style of entrance and ceiling's decoration of the room and the garden design of courtyard, even the wind tower and the number of skylights all have a meaningful function; the more decorated, the more sign of social status of owner; however, the house has been a productive and economic center for the Rayat and Rayati strata (Janeb Allahi, 2006, p. 20). With such a definition for housing that is entirely based on the traits of the behavioral patterns and social status of individuals the housing of Meybud's citizens has been shaped and turned into a pattern (Figure 5a, 5b, 5c).
Figure 5 represent pattern of garden-house in Meybud. These patterns in accordance with social structure of individuals are divided into three groups of Bozorgoon (Salar House), Rayat (house of Zare Mehrjardi) and Rayati (Zandi house). In all sample, the garden appears by the aim of creating shading, cultivating and working, and recreating and mixing among people as an ancient pattern.

Implicit knowledge in the architecture of Meybud can be investigated since its architecture is based on the teacher and student system, and the architect, regarding to the principles and norms of the region, has achieved specific patterns in housing architecture which ensures the needs of the inhabitants; in other words, the tacit knowledge is the origin and source of accepted patterns that have been formed in the residential architecture of Meybud.

\section{Finding}

In the formation of the body, the physical dimensions are very effective and tacit knowledge is one of the most important aspects. The tacit knowledge based on the sustainability of responsive and sustainable patterns of local communities has been accepted and used by Meybud's inhabitants as a well-known old pattern. Interviews on the factors affecting the construction of the Garden-house and its impact on Meybud's housing, which are known as capable sources, indicate that construction is based on demand.

In order to more understand of the impact of tacit knowledge on shaping patterns, a number of citizens were asked to plan their ideal home without any limitations. A number of drawings are shown in Table 1.

The patterns of homes are all derived from the mental standards of the peoples. For example, in all patterns drawn, unconsciously, focusing on the design of spaces around the yard, the extension of the building in the north-south direction and the attention to a particular place for guest is seen. Table 2 analyses these patterns.

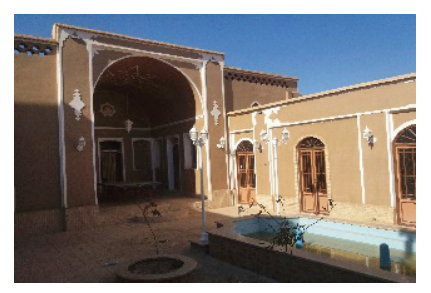

a. Zandi House Small district (Safavid period) (source: authors, 2018)

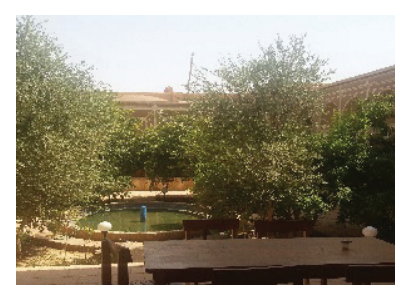

b. Salar house Baghshahi district (Qajar period) (source: authors, 2018)

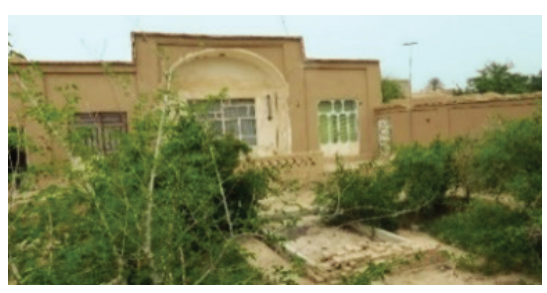

c. House of Zare Mehrjardi Mehrjerd district (Pahlavi period) (source: authors, 2018)

Figure 5. Formation of housing architecture patterns consistent with the tacit knowledge system in Meybud 
Table 1. Ideal housing patterns from Meybod resident's (source: authors, 2018)

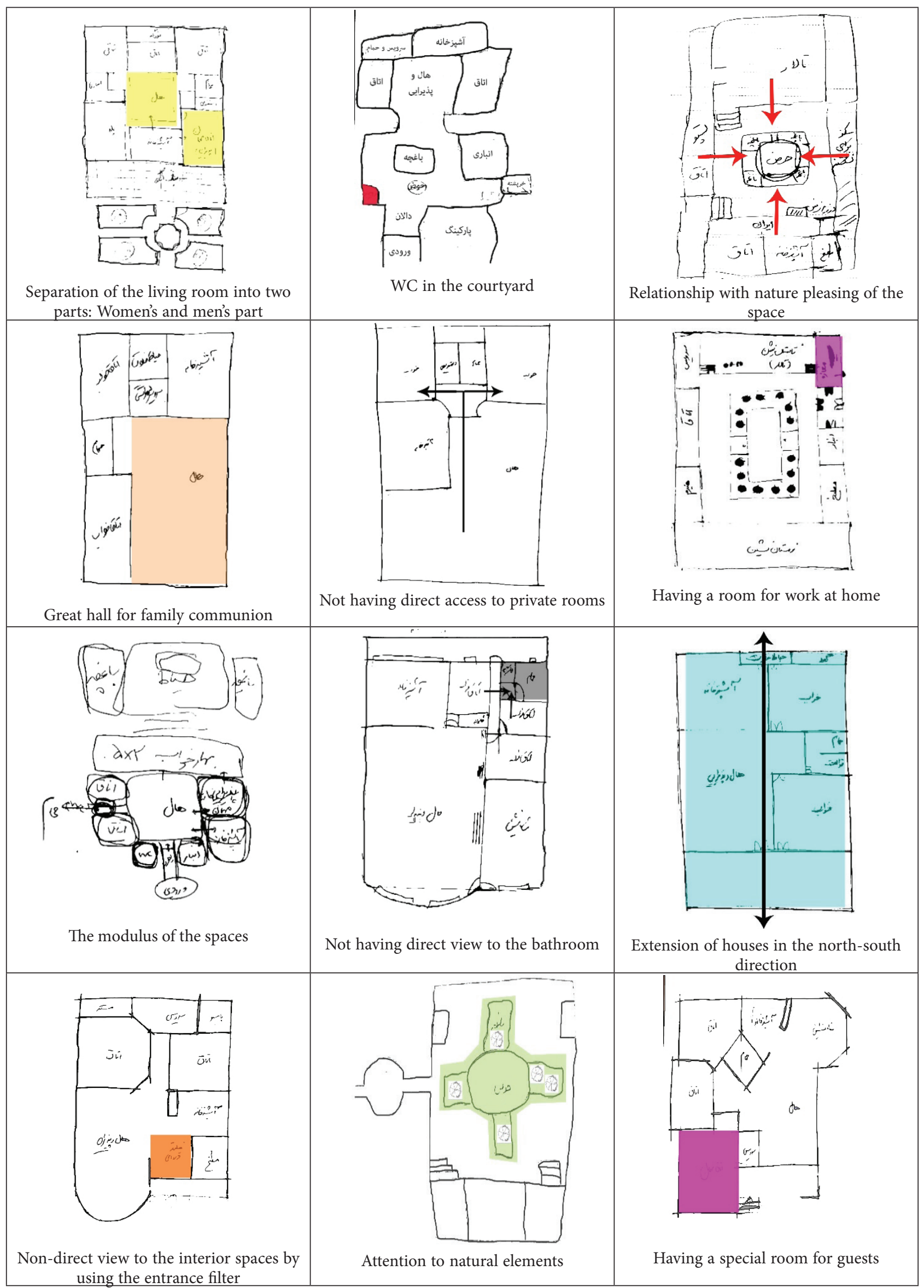


Table 2. Pattern analysis (source: authors, 2019)




By shaping the elements and components the house has turned into a valuable behavioural basis that its boundaries are beyond the touchable demands and has become a place which the intangible and metaphysical demands have come at first place. The findings indicate the presence and relations of the four intervening factors (1). Formation context (nature and climate) (2). Tastes of people (3). Kinship system (4) and architectural thinking (according to the three previous pattern) in the formation of the garden-house pattern. In response to first research's question, i.e. the factors effecting the formation of the Garden-house pattern in Meybud, the relations among items and its adaptation for the foundation of tacit knowledge and field studies, suggest that the formation of the old garden-house pattern, socio-cultural factors (norms), natural-environmental and economic element are as the most important constructive components (according to interviews). Each of these components has been effective in the evolution of this pattern in a measured coherence (Table 3).

The existence of garden, water and shading (considering the climate), in the mental framework of the Meybud's inhabitants, is an undeniable necessity, and this is the most important reason for the formation of the Garden-house pattern, meanwhile the role of the garden-house in livelihood of families should not be neglected (its economic dimension). Accordingly, Garden-house is considered to be focused on livelihood activity. In addition, the combination rings and the dialogues, as a social norm implies that kinship relative, that are derived from social relations, has important role in shaping of garden-house's pattern construction. This is particularly evident in the interviews' comments; in other words, garden-house, in addition to the mentioned roles has provided a center for families, neighbours, and relatives (Figure 6).

There is a direct relation between cognition (understanding tacit knowledge) and creation (production). Basically, the architect provides nothing but a response to the norms. In an architecture based on recognition, the

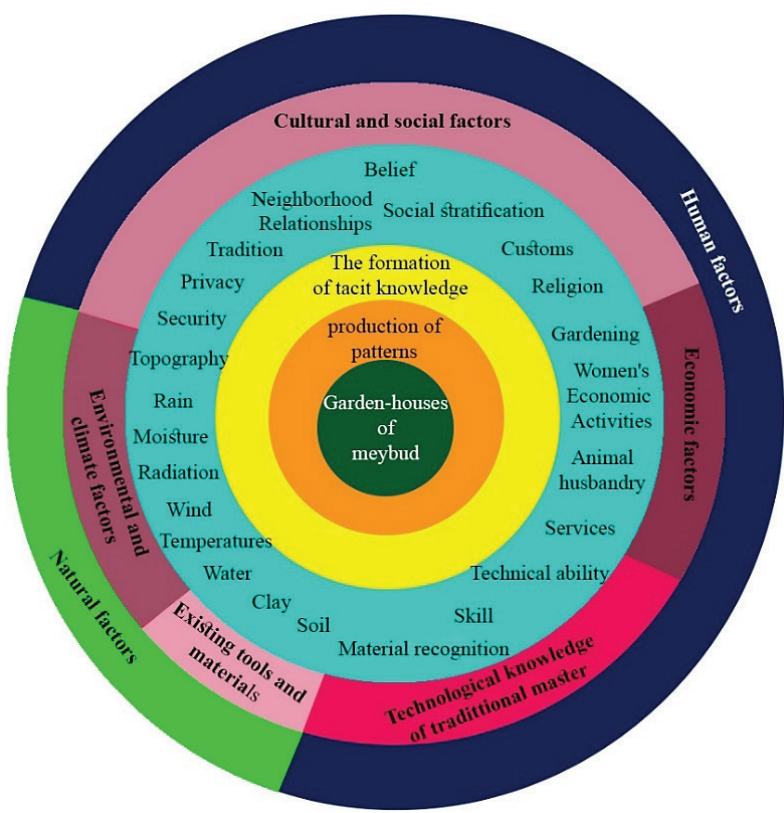

Figure 6. The relationship of tacit knowledge with the production of patterns (source: authors, 2018)

radius of architectural awareness and intellectual backing from society is so deep that provides not just the functions but adds the designed space to the architectural content, and provides a lasting form. The architect creates innovation by full cognition of the capacities (climate and norm) and defiantly the response to these two components is the creativity, ingenuity and utility (Figure 7).

According to the statements above, the Meybud's citizen's aspect of view to housing is related to other important factors beyond the physical needs which is intensified. In this view, the garden-house, the hangout-house, the livelihood-house and the climate-house are the inspiring housing. The interconnections of these functions and concepts causes the continuity of the pattern and gives the identity to the garden-house architecture (Figure 8).

Table 3. effective components on garden-house construction and its representation on Meybud housing (source: authors, 2018)

\begin{tabular}{|c|c|c|}
\hline Examples & Components & Factors \\
\hline $\begin{array}{l}\text { Attention to defence and security issues } \\
\text { (organizational understanding) } \\
\text { Outing in the garden } \\
\text { A special way of life } \\
\text { Gathering place }\end{array}$ & $\begin{array}{l}\text { Religion } \\
\text { Ethnicity and kinship } \\
\text { Relations } \\
\text { Social base } \\
\text { Life style }\end{array}$ & Social and cultural factors \\
\hline $\begin{array}{l}\text { Attention to the climate } \\
\text { The importance of water presence in } \\
\text { housing } \\
\text { Respect for nature and proper use of it }\end{array}$ & $\begin{array}{l}\text { Factors and elements of the climate } \\
\text { Shape and ripeness of the earth } \\
\text { Moisture and rain }\end{array}$ & $\begin{array}{l}\text { Natural and environmental } \\
\text { factors Knowledge }\end{array}$ \\
\hline $\begin{array}{l}\text { Livelihood with garden products } \\
\text { Woman's activities in traditional homes } \\
\text { Providing consumed need of family }\end{array}$ & $\begin{array}{l}\text { Production and service } \\
\text { Activities } \\
\text { Economic resources } \\
\text { available }\end{array}$ & Economic factors \\
\hline
\end{tabular}






Figure 7. Application of tacit knowledge in the production of content (garden-house pattern in Meybud) (source: authors, 2018)



Figure 8. The relations of implicit knowledge and pattern in housing architecture of Meybud (source: authors, 2018)

\section{Conclusions}

The geographic location and climatic structure of Meybud make the construction of the garden-house inevitable. Low rainfall and high tempered summer are the main reasons for creating the garden-house; however, the formation of this pattern must not be viewed as a mere climate point because the attraction of the garden with climate in different regions and territories is not limited to landscape's beauty, but rather related to more complex issue i.e. the anthropology of these lands (Petrochioli, 1994, p. 13). Spatial organizing of garden-house in Meybud, which has become an important source of identity for the Meybud's inhabitants and achieved meaningful context of interconnected areas and, documenting the experiences, has provided the context for the sustainability of this pattern. The formation of garden architecture is formed based on simple structures according to cultural, social dimension, behavioral pattern and demand, and the success of this pattern depends on the recognition of variables such as "norms", "knowledge and tools" and "typical livelihood" and consideration of these features requires the cognition of tacit knowledge. This knowledge is the standard to provide the infrastructure needed to understand the environment and the formation of optimal housing. In Meybud, tacit knowledge with measures derived from environment has provided the most suitable and simplest life model in the house-garden context and changed into a permanent and responsive source, relying on the closeness and comprehension of individuals and the environment, the context for the formation of sustainable housing has been considered. This human resource has continued from the distant past, and it is the most important value that housing of Meybud can be identified with it; hence, it is vital in every situation; it cannot be eliminated; in all circumstances, its sustainability must be sustained.

\section{References}

Albers, J. A, \& Trinidad, A. L. (2006). Knowledge management software; a selection process. CACCI Journal, (1). Retrieved from www.moshaveran.net

Alexander, Ch. (2011). The timeless ways of building $\left(2^{\text {nd }}\right.$ ed, $3^{\text {rd }}$ ed). Translation by Mehrdad Ghiomi Bidhendi. Tehran: Shahid Beheshti University, Printing \& Publishing Center.

Arab, B. (2015). Knowledge management (concepts, principles, goals and models). Tehran.

Barati, N., \& Kakavand, E. (2016). Phenomenological study on the recognition of an ancient notion in Iranian-Islamic architecture. Case study: Tehran artillery square, Square of Naghshe Jahan (Isfahan), Laleh Park (Tehran), Shahzadeh Garden (Mahan). Journal of Bagh-e Nazar, (42), 5-18.

Fadaei, Gh. (2016). Knowledge management and presentation of a new model. Information Research and Public Libraries, 22(1), 15-29.

Farhoodi, F., \& Dorurdi, F. (2008). The necessity of using knowledge management in increasing the quality of activities of modern organizations. Journal of Technology and Information Sciences, 89-104.

Heydari Tafreshi, Gh., Khadivi, A., \& Yousefi, R. (2012). Theories of organization and management in the postmodern world. Tehran. Green culture.

Huysman, M. (2006). It to support knowledge sharing in communication: toward a social analysis. Journal of information technology, 21(3), 51-40.

https://doi.org/10.1057/palgrave.jit.2000053

Irannezhad Parizi, M. (2012). Management in the third millennium. Tehran: Publishing of Managers.

Janeb Allahi, MS. (2006). Forty speeches in anthropology of Meybud. Second and Third Offices, Economic Anthropology. Tehran: Ganjineh Honar Publication.

Kalami, M. (2014). Personal (tacit) knowledge and initial generator of designing: Solutions for using personal knowledge in finding the initial generator at the beginning of the design training (Thesis for doctoral degree in architecture). Shahid Beheshti University. 
Venkitachalam, K., \& Busch, P. (2012). Tacit knowledge: review and possible research directions. Journal of knowledge management, 16(2), 356-371.

https://doi.org/10.1108/13673271211218915

Lazemi Chalak, S., Ansarian, R., \& Mohammad Nejad, S. (2012). The role of tacit KM in implementing enterprise resource planning system. First National Conference on Accounting and Managemen. Natanz, Iran.

Mahroeian, H., \& Forozia, A. (2012). Challenges in managing tacit knowledge: a study on difficulties in diffusion of tacit knowledge in organizations. International Journal of Business and Social Science, 3(19), 303-308.

Mehr Alizadeh, Y., \& Abdi, M. R. (2011). Knowledge management system; Experience of the organization of tax affairs of the country. Ahvaz, Shahid Chamran University.

Miller, Mb. (1997). Participation action research: psychology and social change. Journal of social issue, 53(4), 666-657. https://doi.org/10.1111/j.1540-4560.1997.tb02454.x

Mohammadi Khabazan, S. (2016). The concept of home in Isfahan Safavid era (1rst ed.). Tehran: Persian Book.

Nari Ghomi, M., Tehrani, F., Raja Ghomi, M., Abbaszadeh, M. J., \& Mahalatian, A. (2015). Problem paradigms in architecture: an approach to the problem of a cultur-oriented and application-oriented in architecture. Tehran: Institute of Architecture Science of Royal.

Nonaka, I., \& Takeuchi, H. (1995). The knowledge-creating company (edn.). New York, Oxford: Oxford university press.
Oshtoran, K., \& Emami Meybodi, R. (2010). Tacit knowledge and technology transfer policies with emphasis on information and communication technology (1rst ed). Tehran: Publication of the University.

Petrochioli, A. (1994). Islamic gardens, architecture, nature, landscapes. Translated by Majid Rasekhi, Tehran: Rozane.

Rahimi Ashtiani, Z. (2012). Designing of housing based on residential patterns in Biram Larestan (Master's Thesis). Isfahan Art University.

Sameh, R. (2015). Pattern language, example of designing, design experience based on native teachings (1rst ed). Qazvin: University Jihad Publications.

Sharif, H. R., \& Mohammad Ali Nejad, F. (2012). Pattern language and cognitive psychology. Journal of Safe, 56, 233-240.

Smith, E. A. (2001). The role of tacit and explicit knowledge in the workplace. Journal of Knowledge Management, 5(4), 311321. https://doi.org/10.1108/13673270110411733

Soltani, M., Mansouri, S. A., \& Farzin, A. A. (2012). Adapting the role of the pattern and the concepts based on the experience in the architectural space. Journal of Bagh-e Nazar, (21), 3-14.

Takashi, I., Sakamoto, M., \& Miyake, T. (2011). How to write tacit knowledge as a pattern language: media design for spontaneous and collaborative communities. Procedia - Social and Behavioral science Journal, (26), 46-54. https://doi.org/10.1016/j.sbspro.2011.10.561

Wiig, K. M. (2002). New generation knowledge management: what may we expect? Knowledge Research Institute Inc, 1-9. 